\title{
Fatal cerebellar herniation secondary to Camurati-Englemann's disease
}

\author{
RICHARD K SIMPSON JR, * DUNCAN K FISCHER, * GARY K S E GALL, $\dagger$ \\ JAMES E ROSE*
}

From the Departments of Neurosurgery* and Pathology, $†$ Baylor College of Medicine, Houston, Texas, USA

SUMMARY Suboccipital craniotomy and cervical laminectomy were performed in a patient with Camurati-Englemann's disease to relieve symptoms of medullary compression. In spite of surgical decompression, the patient expired on the fourth postoperative day from cerebellar herniation.

Camurati-Englemann's disease, also known as progressive diaphyseal dysplasia, is an unusual disorder of bone metabolism. ${ }^{1}$ The lesions are primarily characterised by symmetrical, fusiform hyperostosis and sclerosis of long bones and of the cranial base. ${ }^{2}$ Pain in the lower extremities, general muscle weakness, and a waddling gait are the most common neurological disturbances. ${ }^{3}$ Cranial nerve deficits can occur with involvement of the skull. ${ }^{4}$ Surgical treatment has included decompression of the optic or auditory nerves. ${ }^{24}$ Rarely, a patient will have signs and symptoms of increased intracranial pressure (ICP). ${ }^{5}$ Both the aetiology and surgical management of increased ICP in Camurati-Englemann's disease have yet to be clarified.

\section{Case reports}

A 25 year old chemical engineer with Camurati-Englemann's disease was admitted to the Methodist Hospital after a 3 week history of progressive occipital headaches accompanied by neck and shoulder stiffness. He also complained of bilateral hand numbness and difficulty with lower extremity coordination. He occasionally experienced dysphagia, diplopia and loss of taste sensation, yet had no nausea or vomiting. His past history was unremarkable. His family history was negative for congenital bone disorders.

Physical examination revealed a severely macrocephalic man with a prominent maxilla and mandible, and hypertelorism. He had a flattened, broad nasal bridge and large turbinates. His external auditory canals were nearly occluded

Address for correspondence: Richard K Simpson, Jr, Department of Neurosurgery, Baylor College of Medicine, One Baylor Plaza, Houston, Texas, 77030, USA.

Received 5 January 1988.

Accepted 13 June 1988 by bony overgrowth. He had broad, thick extremities and digits. Neurological examination revealed diminished auditory acuity bilaterally and weakness of facial muscles, and nystagmus on lateral gaze. He had a wide based gait, mild dysmetria, hyperactive deep tendon reflexes in his legs, and Babinski's sign was present bilaterally. Fundi were normal.

\section{Methods and results}

Laboratory investigation revealed an alkaline phosphatase of $657 \mathrm{IU} / 100 \mathrm{ml}$ (normal $=25-100 \mathrm{IU}$ ), a parathormone level of $59 \mathrm{pg} / \mathrm{ml}$ (normal $=230-630$ $\mathrm{pg} / \mathrm{ml}$ ). Serum calcium, full blood count, urinalysis and electrocardiogram were normal. A chest radiograph was normal except for thickened ribs and clavicles. A metabolic bone survey showed a diffuse, symmetrical increase in cortical bone thickness with loss of intramedullary cavities. Plain radiograph skull, CT and cerebral angiography were performed but were difficult to interpret because of attenuation caused by thick, dense bone. Magnetic resonance imaging revealed diffuse cranial hyperostosis with no pneumatization of the paranasal or temporal sinuses (fig a). The cerebral hemispheres were normal. There was tonsillar and vermian herniation caudal to $\mathrm{Cl}$.

A decompressive suboccipital craniotomy and $\mathrm{C} 1-\mathrm{C} 2$ laminectomy were performed to decompress the posterior fossa and cervico-medullary junction. The operation was lengthy and technically difficult because of the thickness and density of the bone. Gross inspection of an intraoperative, nondecalcified specimen revealed apparently normal bone. A thick dense dural band between the arch of $\overline{C 1}$ and the foramen magnum was identified and divided. The medulla and spinal cord pulsated normally. As the dura was opened, the patient's temperature rose sud- 

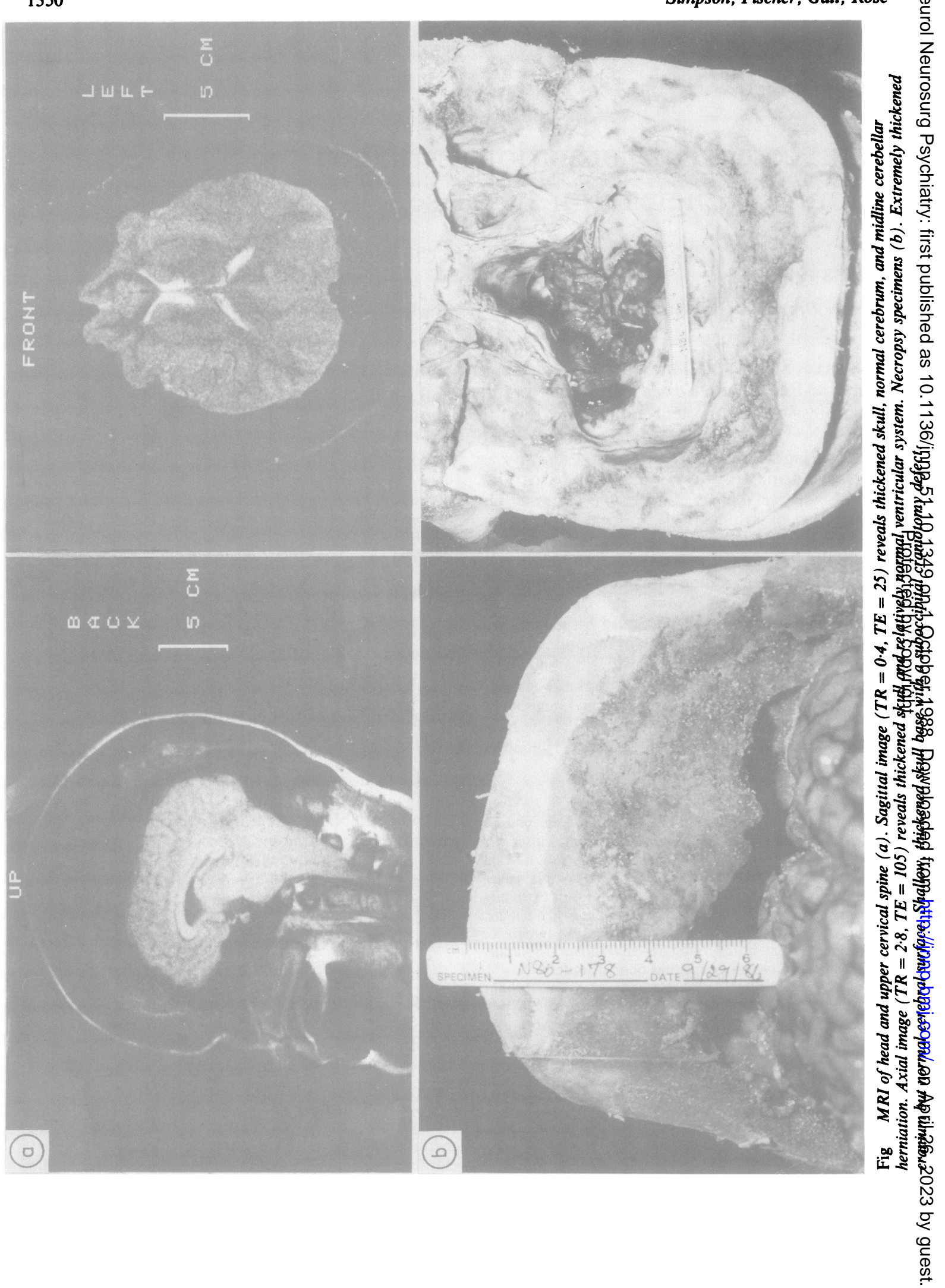
denly to $106^{\circ} \mathrm{F}$, his heart rate reached 150 beats $/ \mathrm{min}$, and he became acidotic $(\mathrm{pH}=7 \cdot 10)$. Malignant hyperthermia was diagnosed; the wound was closed and dantrolene was administered immediately. After operation temperature remained normal; he was lethargic but without focal neurological deficits. On the third day after operation he became suddenly unresponsive. CT of the head was unremarkable. The wound was explored revealing an oedematous, infarcted cerebellum which had herniated into the craniotomy site. The patient died on the fourth day after operation.

Necropsy revealed bilateral hyperostosis and diaphyseal sclerosis of the skull, facial bones, pelvis, femur, tibia and fibula. The calvarium and skull base were markedly and symmetrically thickened and composed of dense cortical bone (fig b). Central or transtentorial herniation of intracranial contents was suspected. There was caudal displacement of the cerebellum through the surgical defect with infarction and pontine haemorrhage. Cerebral architecture and intracranial vasculature were normal.

\section{Discussion}

Progressive diaphyseal dysplasia, or CamuratiEnglemann's disease, is characterised by diffuse symmetrical cortical bone thickening, increased bony diameter, and narrowed medullary cavities of long bones. ${ }^{6}$ Common features also include pronounced thickening of the skull base. ${ }^{78}$ Progressive diaphyseal dysplasia is usually an autosomal dominant disorder with variable penetrance and expression, however, several cases of sporadic occurrence have been documented. ${ }^{24}$ Only 91 cases of progressive diaphyseal dysplasia had been reported. ${ }^{3}$ Diagnosis is often made in childhood and patients have been followed-up for decades. ${ }^{3}$

Radiological evaluation of progressive diaphyseal dysplasia generally reveals diaphyseal sclerosis, enostosis with periostosis, loss of normal trabecular pattern, and dense, sclerotic replacement of normal bone. ${ }^{7}$ Biochemical changes included elevated alkaline phosphatase and urinary hydroxyprolene. ${ }^{9}$ Differential diagnosis commonly includes AlbersSchonberg's disease (osteopetrosis), Paget's disease (osteitis deformans), van Buchem's disease (hyperostosis corticalis generalisata), and Pyle's disease (craniometaphyseal dysplasia). ${ }^{910}$ However, the characteristic long bone features are virtually diagnostic in themselves. ${ }^{7}$

Neurological manifestations of progressive diaphyseal dysplasia include symptoms of cranial nerve dysfunction, generalised weakness, and pain. ${ }^{910}$ The severity of pain and weakness is proportional to the degree of bony involvement. ${ }^{3}$ The precise aetiology of weakness and pain is uncertain. Cranial nerve dysfunction is thought to be secondary to foraminal narrowing and/or increased intracranial pressure. ${ }^{89}$ It is thought that generalised vasculopathy occurs, characterised by thickening of vessel walls and luminal compromise. ${ }^{4710}$ The lumen of intracranial vessels can be further narrowed within the foramina at the skull base. ${ }^{8}$ Such vascular compromise has been suspected as a cause of death, and may contribute other neurological symptoms. ${ }^{4}$

Pain and weakness respond to corticosteroids and mild analgesics. ${ }^{11}$ Calcitonin, cellulose phosphate, glucagon, oestrogens, and testosterone have been used to treat the metabolic derangements, but without success. ${ }^{211}$ Surgical intervention has been reserved primarily for cranial nerve compromise. ${ }^{412}$ Successful optic nerve and auditory canal decompression have been performed; however, operation for increased ICP has been less rewarding. ${ }^{41213}$

Patients with sclerosing bony dysplasias, including progressive diaphyseal dysplasia, Paget's, and AlbersSchonberg's diseases can have increased ICP. ${ }^{210}$ The precise mechanism responsible for increased ICP has remained elusive for over a century. ${ }^{13}$ Several patients with these disorders have succumbed from sudden brainstem compromise. ${ }^{12}$ The surgical procedures that have been used to prevent herniation, have included ventricular shunting, bitemporal craniotomy, and suboccipital craniotomy. ${ }^{81314}$ Bitemporal craniotomy and cranial nerve decompression have been reported to be less useful in some cases owing to the rapid regrowth of bone. ${ }^{2}$ Ventricular shunting has been mildly successful if hydrocephalus is present. ${ }^{14}$ Suboccipital decompression is frequently performed in order to obviate cerebellum and brainstem impaction into the foramen magnum. ${ }^{1314}$ These operations are technically difficult owing to the thickness and density of the skull. ${ }^{51214}$ Successful surgical outcome is temporary and limited, at best. After operation, patients may suffer fatal progression of increased ICP. ${ }^{13}$ Although our case was complicated by malignant hyperthermia, known to cause an increase in ICP, ${ }^{15}$ there was a fatal outcome from progressive herniation despite extensive bony decompression.

Cranial surgery has a limited role in treatment of sclerosing bone dysplasias. A beneficial surgical procedure for treating increased ICP has yet to be devised. Although these diseases are individually rare, taken together they constitute a significant number of patients. Systemic therapy aimed at halting or reversing abnormal bone production is required. Until such treatment becomes available, operative intervention should be exercised with caution. 


\section{References}

1 Griffiths DL. Engelmann's disease. J Bone Joint Surg 1956;38A:312-26.

2 Krohel GB, Wirth CR. Englemann's disease. Am J Ophthalmol 1977;84:520-5.

3 Naveh Y, Kafori JK, Alon U, Ben-David J, Berant M. Progressive diaphyseal dysplasia: Genetics and clinical and radiologic manifestations. Pediatrics 1984;74: 399-405.

4 Sparkes RS, Graham CB. Camurati-Englemann's disease. Genetics and clinical manifestations with a review of the literature. J Med Genet 1972;9:73-85.

5 Mottram ME, Hill HA. Diaphyseal dysplasia. Report of a case. Am J Roentgen 1965;95:162-7.

6 Hundley JD, Wilson FC. Progressive diaphyseal dysplasia. Review of the literature and report of seven cases in one family. $J$ Bone Joint Surg 1973; 55B:461-74.

7 Ramon Y, Buchner A. Camurati-Englemann's disease affecting the jaws. Oral Surg 1966;22:592-9.

8 Van Dalsem VF, Genant HK, Newton TH. Progressive diaphyseal dysplasia. Report of a case with thirty-four years of progressive disease. $J$ Bone Joint Surg
1979;61A:596-8.

9 Smith R, Walton RJ, Corner BD, Gordon IRS. Clinical and biochemical studies in Engelmann's disease (progressive diaphyseal dysplasia). $Q J \mathrm{Med} 1977$; 182:273-94.

10 Beighton $\mathrm{P}$, Hamersma $\mathrm{H}$. Ophthalmological complications in the sclerosing bone dysplasias. Ophthalmic Paediatr Genet 1985;6:129-34.

11 Crisp AJ, Brenton DP. Englemann's disease of bone-a systemic disorder? Ann Rheum Dis 1982;41:183-8.

12 Beighton P, Durr L, Hamersma $\mathbf{H}$. The clinical features of sclerosteosis. A review of the manifestations in twenty-five affected individuals. Ann Intern Med 1976;84:393-7.

13 Culebras A, Feldman RG, Fager CA. Hydrocephalus and dementia in Paget's disease of the skull. $J$ Neurol Sci 1974;23:307-21.

14 Braude BM, Leiman BC, Moyes DG. Etromidate infusion for neuroanaesthesia. A case report. $S A f r$ Med J 1985;20:111-2.

15 Gronert GA. Malignant Hyperthermia. In: Miller RD, ed. Anesthesia. New York: Churchill-Livingstone 1986:1971. 